\title{
Performance evaluation of carbonized rubber seed shell (CRSS) filler as reinforcer in rubber binder
}

\author{
Munirah Onn ${ }^{\text {a, }}{ }^{*}$, Nor Fadilah Mohamad ${ }^{\text {b }}$, Noor Hidayu Abdul Rani ${ }^{b}$, Zafryll Amir Zulkifly ${ }^{\mathrm{c}}$ \\ a Faculty of Applied Sciences, Universiti Teknologi MARA Johor, Pasir Gudang Campus, 81750 Masai, Johor, Malaysıa \\ b Faculty of Chemical Engineering, Universiti Teknologi MARA Johor, Pasir Gudang Campus, 81750 Masai, Johor, Malaysıa \\ c Faculty of Applied Sciences, Universiti Teknologi MARA Perlis, 02600 Arau, Perlis, Malaysia \\ *Corresponding author: munirah591@johor.uitm.edu.my
}

\section{Article history}

Received 27 February 2018

Revised 28 March 2018

Accepted 21 May 2018

Published Online 3 September 2018

\begin{abstract}
The use of rubber-seed shell as a raw material for the production of carbonized filler was investigated. The produced carbonized rubber seed shells (CRSS) waste were characterized by its particle size, density and FTIR value. In this study, the effect of CRSS on the rheological and mechanical properties of rubber had shown great changes and nearly meet the properties of conventional used of filler which is carbon black. Five samples of rubber compounded with different loading of CRSS $(0,10,15,20$ and $30 \mathrm{phr}$ ) were prepared. The higher filler loadings show increment in tensile strength, tensile modulus and hardness but decrease in elongation at break properties. At optimum CRSS loading (20 phr), the tensile strength and tensile modulus (M300) depict positive improvement. Meanwhile, the higher CRSS loading that have less developed structure also will worn the surfaces of rubber compound, thus result in decreasing abrasion resistance index (ARI) value as filler loading increase. This is due to higher CRSS loading will result in poor interaction between rubber matrix and filler content. Lastly, crosslinked density via Flory-Rehner equation depicts solvent uptake decrease linearly by adding more CRSS filler. Therefore, from the conclusive data and observations, the produced CRSS as alternative to current rubber black has great potential to be used as reinforcement filler in rubber compounding along with commercializing the waste materials to the next level.
\end{abstract}

Keywords: Rubber seed shell, carbonized reinforcing filler, tensile test, abrasion resistance, FloryRehner equation

(C) 2018 Penerbit UTM Press. All rights reserved

\section{INTRODUCTION}

Malaysia is one of the leading producers of natural rubber in the world with 1.3 million hectare of area under rubber plantation and each hectare can give an approximate amount of $150 \mathrm{~kg}$ of rubber seeds. Rubber seed shell is obtained from the seeds of the rubber plant (Hevea brasilienses). It is also called as para-rubber or euphorbiaceae. The resource of rubber seed shell is abundant and these seeds were not edible causing it becomes one of the unused waste materials (Hassan et al., 2014).

Fillers are defined as materials that are added to a rubber formulation to lower the compound cost or to improve properties of rubber. Carbon black is the one of many filler used in rubber compounding especially in tyre manufacturing where it is extracted from petroleum which is non-renewable materials. For decades, the use of rubber reinforced with filler such as carbon black and amorphous silica was found in most application in order to improve the end-use performance associated with the increased modulus, abrasion resistance and tensile strength properties (Saad et al., 2009).

Global trends in industries are to minimize the negative impact on the environment, human health, energy and protecting raw materials resources. In this research, the production of green carbonized rubber seed shell (CRSS) waste is developed to find a new alternative to replace current commercialize carbon black filler. Therefore, in this research, rubber seed shell was chosen as a precursor for the production of green CRSS since it is abundantly in Malaysia and have a great potential to replace current commercialize carbon black filler. Therefore, in this research, rubber seed shell was chosen as a precursor for the production of green CRSS since it is abundantly in Malaysia and have a great potential to replace current commercialize carbon black filler. The addition of fillers also requires a balance of formulation for optimum processing properties. Thus, this study also aims to evaluate the optimum loading level of CRSS at 0,10, 15, 20 and $30 \mathrm{phr}$ in ethylene propylene diene (EPDM) as rubber binder for its property and benefit.

\section{METHODOLOGY}

\section{Materials}

EPDM rubber was supplied by Lembaga Getah Malaysia (LGM). Other chemicals including activator (zinc oxide), processing additives (stearic acid), accelerator (mercapta benxothiazoles, MBTS) and crosslinker (sulphur), green color pigments was supplied by Uniworldwide Resources Sdn. Bhd. All materials were commercially obtained from local market.

\section{CRSS preparation}

The rubber seed was collected from Pasir Mas, Kelantan. Rotten rubber seeds were discarded and rubber seed in good condition were dishelled, and dried at $50^{\circ} \mathrm{C}$ for 30 minutes to remove an excess of moisture. After that, the dry rubber seed were crushed using crusher 
machine (Model Retsch GmbH5657 Haan West Germany) into rubber seed particle. The particle was carbonized inside furnace at $600{ }^{\circ} \mathrm{C}$ for 3 hours (Model METM-525 Muffle Furnace) and pulverized until it becomes a fine powder and sieved through mesh size at $150 \mu \mathrm{m}$ using automatic siever shaker (Model Tecnotest Modena Italy 220V 50HV).

Table 1 Compounding ingredients.

\begin{tabular}{ccccccc}
\hline Types & Ingredients & Sample 1 (phr) & Sample 2 $(\mathbf{p h r})$ & Sample 3 (phr) & Sample 4 (phr) & Sample 5 (phr) \\
\hline Rubber & EPDM & 100 & 100 & 100 & 100 & 100 \\
Activator & Zinc Oxide & 5.0 & 5.0 & 5.0 & 5.0 & 5.0 \\
Co-Activator & Stearic Acid & 2.0 & 2.0 & 2.0 & 2.0 & 2.0 \\
Filler & CRSS & 0.0 & 10 & 15 & 20 & 30 \\
Accelerator & MBT & 0.5 & 0.5 & 0.5 & 0.5 & 0.5 \\
Curing Agent & Sulphur & 1.5 & 1.5 & 1.5 & 1.5 & 1.5 \\
\hline
\end{tabular}

\section{Mechanical mixing}

The formulation of compounding ingredients in Table 1 were used and mixed using Banbury internal mixer machine (closed system) to avoid scattering of particles (Model: DW5310A) and sheet out using 2 roll mill machines (Sinan XX 160 A) into a blanket form. The ingredients were prepared according to Table 1 as per formulation sequence and mixed at temperature $170^{\circ} \mathrm{C}$ for three minutes. Rheometer machine (Hung Ta, Model HT-M2000) was used to determine the curing time ( $\mathrm{t} 90)$, scorch time (ts2), and maximum torque $(\mathrm{MH})$. This data was used for molding rubber compound using compression molding (Model: CM 6-0T) and hot press (Vistec Technology, Model: HP-50T).

\section{Measurement}

\section{Tensile properties}

The sheets with $2 \mathrm{~mm}$ in thickness obtained from compression molded were cut into dumbbell shaped by using a Wallace die cutter. By referring to ASTMD 412-06, the tensile test was carried out by using Instron tensile tester machine (model instron 5567) at room temperature with a crosshead speed of $500 \mathrm{~mm} / \mathrm{min}$ and load cell $30 \mathrm{kN}$. Tensile strength is given in megapascals (MPa) by the formula F/A where F is the breaking force in newtons and $\mathrm{A}$ is the initial cross sectional area, in square millimetres.

\section{Abrasion resistance test}

Abrasion test was successfully carried out by using Akron Abrasion Tester (Hung Ta, Model: HT-8022) and referred to a standard rubber (ASTM D394). The test procedure includes trial run, running in period and five test runs. The procedure started with the clamping process of the weighted sample into the spindle. Abrasion resistance can be expressed as abrasion resistance index (ARI) from the equation:

$$
A R I=\frac{V s}{V t} \times 100
$$

where:

$\mathrm{Vt}$ : Volume loss (in $\mathrm{mm}^{3}$ ) of the test rubber

Vs : Volume loss (in $\mathrm{mm}^{3}$ ) of the standard rubber determined under the same test conditions

\section{Density test}

Density test was carried out in accordance to International Organization of Standardization (ISO) 2781. Density measurement was measured directly by immersing the sample in the container by using densimeter analyzer (Densometer EW-300SG).

\section{Crosslink density test}

Solvent swelling measurement was carried out to determine the number of crosslink per gram (moles crosslink/g). Sample was immersed in toluene for 72 hours at room temperature. The FloryRehner equation was used for determination of crosslinking density 3 :

$$
-\ln \left(1-\Phi_{r}\right)+\Phi_{r}+x 1 \Phi_{r} 2=V_{o} n /\left(\Phi_{r} 1 / 3-\Phi_{r} / 2\right)
$$

where: $\mathrm{n}=$ Crosslink density or effective number of chains in a real network per unit volume or number of crosslink per gram (moles crosslink / g) $\mathrm{X}_{1}=$ Flory Huggins polymer solvent interaction parameter of toluene solvent (0.391)

$\mathrm{V}_{\mathrm{o}}=$ Molar volume of toluene solvent (106.2)

$\Phi_{\mathrm{r}}=$ Volume fraction of polymer in a swollen mass and calculated by the expression:

$$
\frac{\Phi_{r}=}{\left(W_{i}-W_{w}\right)+\left(W_{s^{-}}-W_{i}\right) / W_{w}}
$$

where:

$\mathrm{W}_{\mathrm{i}}=$ Weight of dry rubber in air

$\mathrm{W}_{\mathrm{s}}=$ Weight of the rubber sample in swollen

$\mathrm{W}_{\mathrm{w}}=$ Weight of rubber immersed in water

$\rho_{\mathrm{s}}=$ Density of toluene $; 0.87 \mathrm{~g} / \mathrm{cm}^{3}$

\section{Durometer hardness test (Shore A)}

For hardness test, $6 \mathrm{~mm}$ thick of round specimen was measured with Shore A durometer which it utilizes a spring to provide intending forces. For this test, five sections in each sample were tested at different points to get the appropriate results by using the average hardness of those parts as the actual results by referring to ASTM D2240.

\section{Characterization}

\section{Fourier transform infrared spectroscopy (FTIR)}

The surface organic functional groups of the samples were analyzed using FTIR spectroscopy (Pelkin Elmer Spectrum One) by referring ASTM E168 as the standard method. The solid RCSS particles was applied on Perkin Elmer Spectrum One FTIR with resolution 16 and ranging between a wavenumber of $400-4000 \mathrm{~cm}^{-1}$ at a resolution of $5 \mathrm{~cm}^{-1}$ for analysis.

\section{Differential scanning calorimetry (DSC)}

The test was carried out by using a differential scanning calorimeter (Mettler-Toledo 822). The samples were first heated at the rate of $20{ }^{\circ} \mathrm{C}$ minute from $-50{ }^{\circ} \mathrm{C}$ to $200{ }^{\circ} \mathrm{C}$. DSC study was carried out according to ASTM D 3418-82 and calorimeter was calibrated with indium reference. Sample in size range of 5.0-8.0 $\mathrm{mg}$ was placed in a sealed aluminium pan and an empty aluminium pan was used as a reference and nitrogen gas was purge at $20 \mathrm{~mL} / \mathrm{min}$. The DSC data measure the heat flow as it is heated and graph data was presented as heat flow against temperature plot.

\section{RESULTS AND FINDINGS}

\section{Characterization}

Fourier Transform Infrared (FT-IR) Spectroscopy of carbonized rubber seed shell was given in Figure 1 respectively. From the figure, a broad adsorption peak showed at $3235.36 \mathrm{~cm}^{-1}$ which attributed to $\mathrm{O}-\mathrm{H}$ stretching functional group and this indicated the presence of hydroxyl group in the sample. The band at $1576.38 \mathrm{~cm}^{-1}$ corresponded to $\mathrm{C}=\mathrm{C}$ stretching in aromatic ring and peak around $1450 \mathrm{~cm}^{-1}$, indicating the presence of pyrones and aromatic groups. 


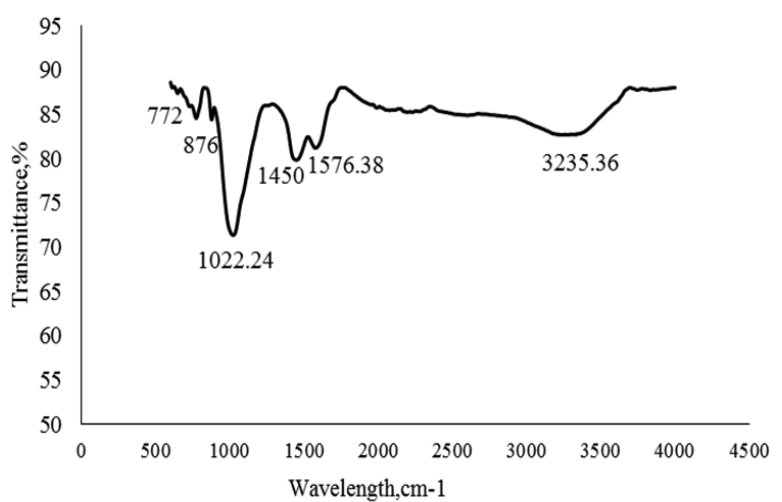

Fig. 1 FT-IR spectra of carbonized rubber seed shell.

This sample also shows important adsorption peak at $1022.24 \mathrm{~cm}^{-}$ ${ }^{1}$ which refer to $\mathrm{C}-\mathrm{O}$ stretching functional group. The weak peaks around $876 \mathrm{~cm}^{-1}$ and $772 \mathrm{~cm}^{-1}$ indicate C-H out-of-plane bending in aromatic ring. As a result, the trend of the FT-IR spectrum for the carbonized carbon revealed complex surface as by presence of several peaks. According to previous researches by (Onn et al., 2014), the carbonized samples exhibit more peaks than that found in the activated carbons (Hamid et al., 2014). This is showed that some reorganization of the surface oxides on subjection to activation at the high temperature occurred.

Table 1 Result for differential scanning calorimeter (DSC).

\begin{tabular}{|c|c|c|c|c|c|}
\hline & Ophr & $10 \mathrm{phr}$ & $15 \mathrm{phr}$ & 20phr & $30 \mathrm{phr}$ \\
\hline $\begin{array}{c}\text { Onset }\left({ }^{\circ} \mathbf{C}\right) \\
\text { Peak }\left({ }^{\circ} \mathbf{C}\right) \\
\text { End }\left({ }^{\circ} \mathbf{C}\right) \\
\text { Area }(\mathbf{m J}) \\
\text { delta } H(\mathbf{J} / \mathbf{g}) \\
\\
\text { onset } \\
\text { Peak } \\
\text { End } \\
\text { Area }(\mathbf{m J}) \\
\text { delta } H(\mathbf{J} / \mathbf{g})\end{array}$ & $\begin{array}{c}\text { 1peak } \\
38.15 \\
47.87 \\
54.28 \\
12.834 \\
1.8399 \\
2 \text { peak } \\
86.32 \\
102.89 \\
121.07 \\
22.957 \\
1.8399\end{array}$ & $\begin{array}{c}\text { 1peak } \\
39.4 \\
46.39 \\
53.94 \\
15.709 \\
2.9923 \\
2 \text { peak } \\
113.95 \\
115.39 \\
119.48 \\
6.464 \\
1.2312\end{array}$ & $\begin{array}{c}\text { peak } \\
39.02 \\
46.53 \\
54.72 \\
18.369 \\
3.0703 \\
2 \text { peak } \\
76.52 \\
99.21 \\
115.8 \\
26.875 \\
4.4919\end{array}$ & $\begin{array}{c}\text { 1peak } \\
40.57 \\
47.77 \\
55.52 \\
28.431 \\
3.6264 \\
2 \text { peak } \\
82.58 \\
100.11 \\
114.59 \\
43.2 \\
5.51\end{array}$ & $\begin{array}{c}\text { 1peak } \\
38.2 \\
46.44 \\
53.41 \\
15.471 \\
3.0141 \\
2 \text { peak } \\
63.52 \\
98.78 \\
122.09 \\
59.263 \\
11.5456\end{array}$ \\
\hline
\end{tabular}

The compounded EPDM rubber prepared by different CRSS amount show a similar melting behavior both as to the depression of the melting point and broadening of the melting range with increased its density value. EPDM contain a meltable ethylene and propylene part which is crystalline component. From the table, there are 2 peak appear on the graph and the differences in PHR depict only slightly differences on melting temperature (delta $\mathrm{H}, \mathrm{mJ}$ ) and heat of melting (area, $\mathrm{J} / \mathrm{g}$ ) . All samples exhibits it $\mathrm{Tg}$ around 46.39 to $47.87{ }^{\circ} \mathrm{C}$ and undergoes melting of its crystalline ethylene component at temperature around 98.78 to $115.38{ }^{\circ} \mathrm{C}$. Only from peak 2 , it shows significant increase for melting temperature (delta $\mathrm{H}$ ) and heat of melting from $22.957 \mathrm{~mJ}$ and $1.8399 \mathrm{~J} / \mathrm{g}$ without CRSS and after $30 \mathrm{phr}$ addition, the value increase up to $59.263 \mathrm{~mJ}$ and $11.5456 \mathrm{~J} / \mathrm{g}$. It shows good physical interactions between EPDM rubber and CRSS would delay and require high energy to melt the rubber compound.

\section{Physical testing}

Table 2 Abrasion resistance test result.

\begin{tabular}{|c|c|c|c|}
\hline $\begin{array}{l}\text { CRSS } \\
\text { loading } \\
\text { (phr) }\end{array}$ & $\begin{array}{l}\text { Mean value } \\
\text { of } 5 \text { test run } \\
(\mathrm{mg})\end{array}$ & $\begin{array}{l}\text { Volume loss } \\
\qquad\left(\mathrm{mm}^{3}\right)\end{array}$ & ARI (\%) \\
\hline 0 & 0.2192 & 0.2404 & 699.56 \\
\hline 10 & 0.2058 & 0.2237 & 751.81 \\
\hline 15 & 0.1760 & 0.1868 & 900.32 \\
\hline 20 & 0.1273 & 0.1319 & 1275.06 \\
\hline 30 & 0.1388 & 0.1449 & 1160.66 \\
\hline
\end{tabular}

From the result above, the abrasion resistance index (ARI) show positive increment from $0 \mathrm{phr}$ to $20 \mathrm{phr}$ loading of CRSS, but slightly decrease when the CRSS loading were increased up to $30 \mathrm{phr}$. The incorporation of CRSS as filler with the rubber matrix provide the adhesion between the polymer chains, thus gives high strength to counter the friction under dynamic and repetition movement, compare to the raw EPDM rubber that contain zero CRSS, it is in gum state and offer poor adhesion properties (Mostafa et al., 2009). Although the addition of CRSS improve the abrasion resistance properties of the rubber, but the quantity and the quality of the filler also need to take into account as the stiffness of rubber will increase as the filler loading increase but it depends on the quality and quantity of the filler (Arayapranee \& Rempel, 2013). As the CRSS loading was up to $30 \mathrm{phr}$, it disturb the molecular structure of the rubber that lead to the rubber surface to become worn out and the filler distribution also become inconsistent. The rubber surface become easily ruptured, thus making it can't resist the abrasion force anymore. Therefore, it can be concluded that the optimum CRSS loading to give the best ARI value was at $20 \mathrm{phr}$.

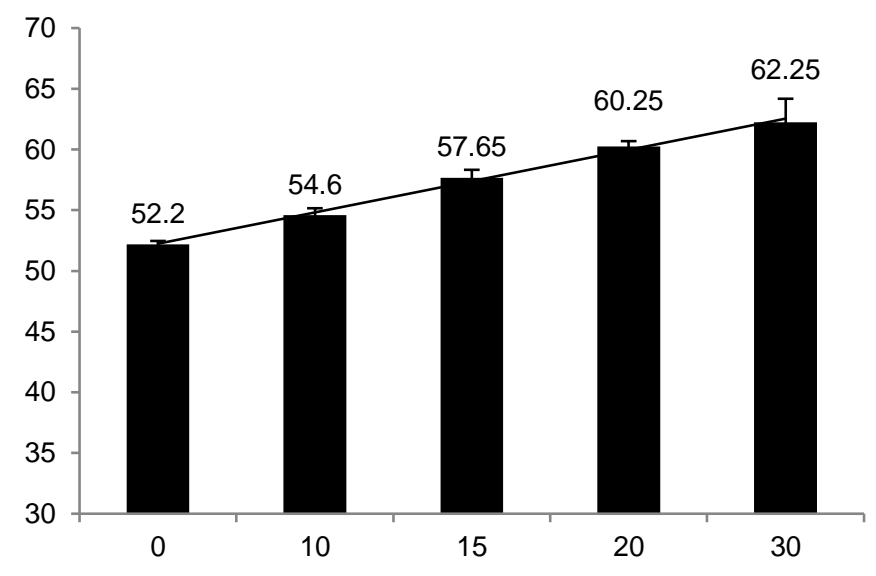

Fig 2 Graph for hardness value (shore A) against phr loading.

Hardness test is used as indication for the rubber rigidity upon moderate stress that need to be focused during the service application. The most popular method of rubbers hardness is the shore A in which is performed the measurement with an instrument called a durometer, based on the penetration of a frusto-conical tip against a calibrated metal spring reaction (Arguello \& Santos, 2016). The summary for each rubber vulcanizate hardness test result is shown in the Figure 2 above. From the result, the hardness value is spotted to be directly proportional to the CRSS loading, as the graph of hardness value keep increasing with increasing of filler loading. The increasing in hardness value is attributed by the cross linking effect between the CRSS and rubber matrix. As the CRSS loading increase, the distance between the CRSS aggregates will come close together to promote strong interaction between the aggregate thus, giving rise to an additional network, known as filler-filler network. This filler-filler network induced high cross linking effect that able to improve the hardness properties of rubber. This highly crosslink rubber will have ordered particles arrangement that able to support and transmit the force that had being applied among themselves. This will make their hardness value depict positive increment, thus increase the rigidity of the rubber. At $0 \mathrm{phr}$, the hardness value is quite low due to the less crosslinked rubber structure that provide greater surface area among rubber particles that allow them to slide pass each other when the force is being applied. Thus, in this state, the rubber still has the elastic property and seems to feel smoother and shows smaller hardness value.

Tensile strength test was used to measure the ability of samples to withstand the pulling stress as well as indicator to measure the maximum load can sustain by the specimen during the test. From Figure 3 below, the tensile strength values keep increasing until it reached optimum CRSS loading at $15 \mathrm{phr}$. 


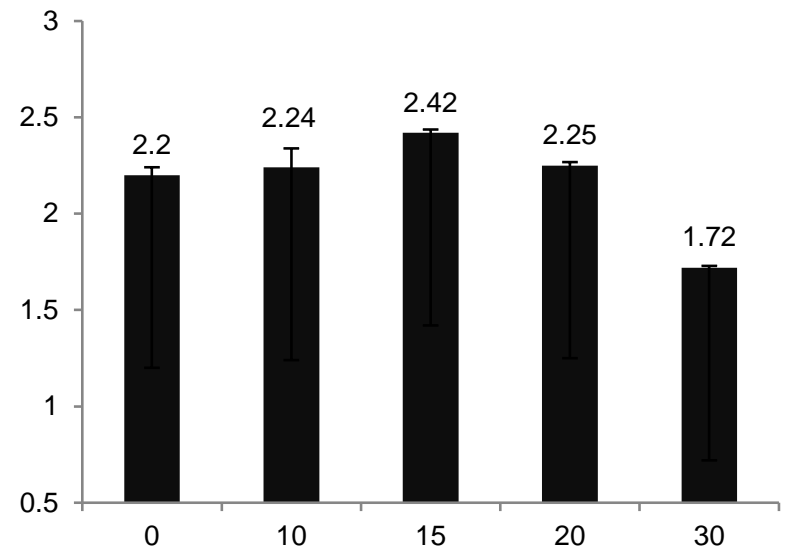

Fig. 3 Graph for tensile strength (mpa) value against phr loading.

According to Mostafa (2009), poor mechanical strength of rubber vulcanizate can be improved by addition of filler (Mostafa et al., 2009). As the CRSS being added above $15 \mathrm{phr}$, the tensile strength of vulcanized EPDM start to going down. Thus, at $15 \mathrm{phr}$, the fillers seem to have better dispersion and interaction with rubber matrix, forming good rubber-filler interactions. These interactions help in promoting efficient stress transfer mechanism from the rubber matrix to the filler thus making the rubber can withstand high tensile force before failure. According to table 3 , the rubber has high cross linking density that lead to high tensile strength compare to the original gum strength of the raw rubber that do not has rubber-filler interactions to support their strength. The carbonization process and selected size of CRSS which is $150 \mu \mathrm{m}$ also contribute to the high tensile strength of rubber. These fine particles size pose high surface area per volume, thus the physical interaction between filler and rubber can be achieved to maximum level, leading to better stress transfer mechanism, forming a high strength rubber. The smaller the particles size will give high degree of reinforcement compared to the larger one (Muniandy, Ismail, \& Othman, 2012). However, as the CRSS loading was increased to $30 \mathrm{phr}$, the tensile strength start to decrease abruptly. According to Arguello \& Santos (2016), when the tensile strength is reduced, it indicates that the rubber had reached its filler loading limit. At high filler loading, the cross link density become overload, thus reduce the elasticity properties of rubber. The rubber will undergo brittle like property and will easily fail when high force being given (Chigondo, Shoko, Nyamunda, Guyo, \& Moyo, 2013).

Tensile modulus or also known as Young's Modulus is the measure of stiffness of an elastic material when being subjected to stretch or compress force. The tensile modulus at $300 \%$ (M300) strain of EPDM reinforced with CRSS was presented in Table 3. Tensile modulus is measured at M300 because at 300\% elongation, sufficient strain orientated crystallization will have occurred to give some stress enhancement. The tensile modulus values increased with the increment loadings of CRSS until $20 \mathrm{phr}$ and the values started to decrease beyond $20 \mathrm{phr}$, which is at $30 \mathrm{phr}$ loading. From the volume fraction, density and crosslink density result above, the values keep increasing with increasing addition of CRSS. This phenomenon is same as in modulus, in which the rubber keeps binding up with the CRSS until it reached it loading limit. As the filler content in the rubber increased, the formation of crosslinks density also increases in which making the rubber becomes denser. The incorporation of filler loadings and rubber matrix plays an important role in determining the tensile modulus values. According to ${ }^{8}$ the values of tensile modulus increased as the rubber filler interaction increased ${ }^{9}$. As for that, above $20 \mathrm{phr}$, the rubber filler interaction become unstable due to the destruction of rubber matrix structure by bulkiness of CRSS, causing the rubber to loss their elastic ability. This situation makes the inability of filler to support the stress transferred from the rubber matrix. Therefore, the optimum loading of CRSS is $20 \mathrm{phr}$ as it can give the highest value of tensile modulus, allowing the rubber to perform well under the applied force.

Table 3 Value for tensile modulus, elongation at break, volume fraction, crosslink density by flory rehner equation and density.

\begin{tabular}{|c|c|c|c|c|c|}
\hline $\begin{array}{c}\text { CRSS loading } \\
\text { (phr) }\end{array}$ & $\begin{array}{c}\text { Tensile Modulus } \\
\text { (M300) }\end{array}$ & $\begin{array}{c}\text { Elongation at } \\
\text { break (\%) }\end{array}$ & $\begin{array}{c}\text { Volume fraction, } \Phi_{\mathrm{r}} \\
\left(\mathrm{cm}^{3}\right)\end{array}$ & $\begin{array}{c}\text { Crosslink } \\
\text { density, (n) }\end{array}$ & $\begin{array}{l}\text { Density } \\
\left(\mathrm{g} / \mathrm{cm}^{3}\right)\end{array}$ \\
\hline 0 & 1.63 & 487.24 & 0.211 & $1.613 \times 10^{-4}$ & 0.912 \\
\hline 10 & 2.36 & 484.95 & 0.220 & $1.720 \times 10^{-4}$ & 0.920 \\
\hline 15 & 3.18 & 558.67 & 0.249 & $2.871 \times 10^{-4}$ & 0.942 \\
\hline 20 & 3.63 & 528.24 & 0.279 & $3.392 \times 10^{-4}$ & 0.958 \\
\hline 30 & 3.62 & 426.98 & 0.289 & $3.645 \times 10^{-4}$ & 0.965 \\
\hline
\end{tabular}

Elongation at break is the ability of material to resist changes in shape without crack formation and is expressed in percentage, in which the percentage of original benchmark length achieved before break. Table 3, shows the result of elongation at break. From the result above, the percent of elongation at break decrease as with the increments in addition of CRSS. This is due to the dominant effect of CRSS that give the poor interactions between rubber and filler interaction. From the results, it can be conclude that high loading of CRSS had reduce the amount of rubber particle thus reducing the rubbery and elastic properties and as a result, it lead to compounded rubber easy to break under stress. Therefore, from the elongation at break result, it can be conclude that the optimum loading of CRSS is $20 \mathrm{phr}$.

\section{CONCLUSION}

The performance of CRSS as a reinforcer filler in rubber binder was investigated. These results showed an enhancement in tensile strength of 2.42 mpa compared to the unfilled EPDM blend. The maximum elongation at break obtained at $15 \mathrm{phr}$ CRSS loading was $558.67 \%$, which is $12.8 \%$ higher compared to unfilled EPDM blend. The melting temperature depict the rubber compound will fully melt at temperature around $100 \circ \mathrm{C}$ for all CRSS loading. Lastly, the optimum loading of CRSS is $20 \mathrm{phr}$ in which the value of abrasion resistance index and tensile modulus is at the highest in which $1275.06 \%$ and 3.63 $\mathrm{MPa}$ respectively compared to other formulation. These mechanical properties enhancements proved the suitability of CRSS as potential reinforcing filler in EPDM blend. Rubber producing countries can use this kind of project not only to solve their ecological problems but also to improve their economy.

\section{REFERENCES}

Arayapranee, W., Rempel, G. L. 2013. Effects of polarity on the filler-rubber interaction and properties of silica filled grafted natural rubber composites. Journal of Polymers, 2013, Article ID 279529.

Arguello, J., Santos, A. 2016. Hardness and compression resistance of natural rubber and synthetic rubber mixtures. Paper presented at the Journal of Physics: Conference Series.

Chigondo, F., Shoko, P., Nyamunda, B. C., Guyo, U., Moyo, M. 2013. Maize stalk as reinforcement in natural rubber composites. International Journal of Scientific \& Technology Research, 2, 6, 263-271.

Hamid, S. B. A., Chowdhury, Z. Z., Zain, S. M. 2014. Base catalytic approach: A promising technique for the activation of biochar for equilibrium sorption studies of copper, $\mathrm{Cu}$ (II) ions in single solute system. Materials, $7,4,2815-2832$

Hassan, S., Ishak, M., Ismail, K., Ali, S., Yusop, M. 2014. Comparison study of rubber seed shell and kernel (Hevea brasiliensis) as raw material for biooil production. Energy Procedia, 52, 610-617.

Mostafa, A., Abouel-Kasem, A., Bayoumi, M., El-Sebaie, M. 2009. Effect of carbon black loading on the swelling and compression set behavior of SBR and NBR rubber compounds. Materials \& Design, 30, 5, 1561-1568. 
Muniandy, K., Ismail, H., Othman, N. 2012. Biodegradation, morpholgical, and ftir study of rattan powder-filled natural rubber composites as a function of filler loading and a silane coupling agent. BioResources, 7, 1, 09570971.

Onn, M., Nor, H., Wan Ali, W. 2014. Development of solid rocket propellant based on isophorone diisocyanate-hydroxyl terminated natural rubber binder. Jurnal Teknologi (Sciences and Engineering), 69, 2, 53-58.

Saad, I., Fayed, M. S., Abdel-Bary, E. 2009. Effects of carbon black content on cure characteristics, mechanical properties and swelling behaviour of 80/20 NBR/CIIR blend. Paper presented at the 13th International Conference on Aerospace Sciences and Aviation Technology, Paper: ASAT-13-CA-06. 